\title{
SUSTANCIAS OXÍGENO REACTIVAS (ROS) EN SEMEN CONGELADO-DESCONGELADO DE PORCINO*
}

\author{
Diana Vasco Mora ${ }^{1}$, Marta Hernández Meroño², Juan María Vásquez², Emilio Martínez ${ }^{2}$ y Jordi Roca² \\ ${ }^{1}$ Unidad de Investigación Científica y Tecnológica, Área de Investigación Porcina, Universidad Técnica Estatal de \\ Quevedo, km 11/2 vía Quevedo - Santo Domingo, C. P. 73. Quevedo, Los Ríos, Ecuador. dianav350@yahoo.com. \\ ${ }^{2}$ Departamento de Medicina y Cirugía Animal, Facultad de Veterinaria, Universidad de Murcia, Campus de \\ Espinardo, C. P. 30071. Murcia, España.
}

\begin{abstract}
RESUMEN
La generación de ROS fue medida por citometría de flujo en muestras espermáticas descongeladas incubadas sin (niveles basales) o con (niveles inducidos) un inductor de ROS ( $1 \mathrm{mM}$ de tert-butyl hidroperóxido) por $30 \mathrm{~min}$ a $39^{\circ} \mathrm{C}$ y $5 \%$ de $\mathrm{CO}_{2}$. Además, fueron simultáneamente teñidas con 2', 7'-diacetato de diclorodihidrofluoresceína, acetil ester ( $1 \mathrm{mM}, \mathrm{CM}-\mathrm{H}_{2}$ DCFDA), para estimar la producción de ROS e, ioduro de propidio $(1.5 \mathrm{mM})$ para excluir la población espermática muerta. Los eyaculados de nueve verracos fueron congelados con $3 \%$ de glicerol y descongelados a $\approx 1200$ ó $\approx 1800{ }^{\circ} \mathrm{C} \mathrm{min}^{-1}$. La producción de ROS fue medida a los $0,60,120,240$ y 360 min en muestras mantenidas a $21-23{ }^{\circ} \mathrm{C}$ (no incubadas), o a $39^{\circ} \mathrm{C}$ y $5 \%$ de $\mathrm{CO}_{2}$ (incubadas). La velocidad de descongelación no registró influencia $(\mathrm{P}>0.05)$ sobre la producción de ROS. La generación de ROS fue constante $(\mathrm{P}>0.05)$ en el tiempo en las muestras no incubadas, pero mostró un incremento progresivo en las muestras incubadas, siendo significativa $(\mathrm{P}<0.05)$ desde los 120 min en niveles basales ó 60 min de incubación en niveles inducidos. Además, una significativa variabilidad eyaculado/verraco fue evidente, tanto en niveles basales como inducidos en las muestras incubadas. La producción de ROS basal e inducida estuvo significativamente $(\mathrm{P}<0.01)$ correlacionada con la calidad espermática. La técnica utilizada es de gran utilidad para evaluar capacidad funcional en espermatozoides congelados-descongelados; sin embargo, se requieren estudios adicionales para estandarizar la misma y establecer umbrales indicativos de pérdida de calidad espermática.
\end{abstract}

Palabras clave: Verraco, criopreservación, ROS, calidad espermática.

\begin{abstract}
The ROS generation was measured by flow citometry in thawed sperm samples incubated without (basal levels) or with (induced levels) a ROS inductor ( $1 \mathrm{mM}$ tert-butyl hydroperoxide) for $30 \mathrm{~min}$ at $39^{\circ} \mathrm{C}$ and $5 \% \mathrm{CO}_{2}$. Sperm cells were simultaneously stained with 2', 7'-dichlorodihydrofluorescein diacetate, acetil ester (1 mM, CM$\mathrm{H}_{2}$ DCFDA), to estimate the production of ROS, and propidium iodide $(1.5 \mathrm{mM})$ to exclude dead sperm from the analysis. The ejaculates from nine boars were frozen with $3 \%$ of glycerol and warmed at $\sim 1200$ or $\sim 1800^{\circ} \mathrm{C} \mathrm{min}{ }^{-1}$. The ROS production was measured at $0,60,120,240$ y $360 \mathrm{~min}$ in sperm samples hold at $\sim 21-23{ }^{\circ} \mathrm{C}$ (not incubated) or at $39^{\circ} \mathrm{C}$ and $5 \% \mathrm{CO}_{2}$ (incubated) over time. Warming rate had not influence $(\mathrm{P}>0.05)$ on ROS production. ROS generation was constant $(\mathrm{P}>0.05)$ over time in not incubated samples, but it showed a progressive increase in incubated samples, being it significant $(\mathrm{P}<0.05)$ from the $120 \mathrm{~min}$ in basal levels or $60 \mathrm{~min}$ of incubation in induced levels. Significant $(\mathrm{P}>0.01)$ ejaculate/boar variability was evident in both basal and induced ROS production in the incubated sperm samples. Both basal and induced ROS production were significantly $(\mathrm{P}<0.01)$ correlated with the percentages of total and rapid progressive, motile and viable spermatozoa. The technique is of great utility to evaluate functional capacity in frozen-thawed sperms; however, additional studies are required to standardize the same one and to establish indicative thresholds of sperm quality loss.
\end{abstract}

Key words: Boar, cryopreservation, ROS, sperm quality

\section{INTRODUCCIÓN}

*Parte de investigación realizada en el Departamento de Medicina y Cirugía Animal, Facultad de Veterinaria, Universidad de Murcia, España, para optar por el título de Master en Porcinotecnia.

Recibido: Septiembre, 2007. Aceptado: Noviembre: 2007.

Publicado como ARTíCULO en Ciencia y Tecnología 1: 23-29. 2008.

En los últimos años, nuevos sistemas para envasar las dosis espermáticas (Eriksson y Rodríguez-Martínez, 2000); la optimización del protocolo de criopreservación (Carvajal et al., 2004) y la necesidad de complementar los diluyentes con antioxidantes (Roca et al., 2004 y 2005) han repercutido positivamente en mejorar la calidad espermática post-descongelación; sin embargo, sigue 
siendo un objetivo mejorar los rendimientos productivos del semen criopreservado.

Las ROS son producidas bajo condiciones aeróbicas por todas las células vivas (Brouwers et al., 2005). En los espermatozoides es un proceso fisiológico requerido para que tenga lugar la capacitación y reacción acrosómica (de Lamirande et al., 1998; O'Flaherty et al., 2006). Parte de la reducción en la motilidad y fertilidad espermática asociada con la criopreservación podría ser debido al daño oxidativo de una excesiva o inapropiada formación de ROS (Guthrie y Welch, 2006). Este estrés funcional terminará a corto plazo con la muerte de los espermatozoides que la experimentan y, además, por la liberación del exceso de ROS, potenciará el fenómeno de peroxidación lipídica en los espermatozoides que todavía mantenían la funcionalidad, lo cual da lugar al "envejecimiento prematuro", que provocará la muerte espermática en corto período de tiempo (Saleh y Agarwal, 2002; Brouwers et al., 2005).

El objetivo de esta investigación fue evaluar la influencia de la velocidad de descongelación y el tiempo de conservación post-descongelación en la producción de ROS por parte de los espermatozoides de verraco; y determinar la posible correlación entre la generación de ROS y los parámetros habituales de calidad espermática.

\section{MATERIALES Y MÉTODOS}

La investigación se realizó en el Laboratorio de Andrología, Departamento de Medicina y Cirugía Animal, Universidad de Murcia, España. Se colectaron los eyaculados de nueve verracos híbridos comerciales (Landrace, Duroc, Large White y Yorkshire), fértiles y de dos a cuatro años de edad, pertenecientes a las empresas Batallé S.A., Proinserga S.A. y UVE S.A. Inmediatamente después, la fracción rica fue diluida $1: 1$ (v/v) en BTS (Beltsville Thawing Solution; compuesta de $205 \mathrm{mM} \mathrm{L}^{-1}$ glucosa, $20.39 \mathrm{mM} \mathrm{L}^{-1} \mathrm{NaCl}, 5.40 \mathrm{mM}$ $\mathrm{L}^{-1} \mathrm{KCl}, 15.01 \mathrm{mM} \mathrm{L}^{-1} \mathrm{NaHCO}_{3}, 3.35 \mathrm{mM} \mathrm{L}{ }^{-1}$ EDTA, $50 \mu \mathrm{g} \mathrm{mL} \mathrm{m}^{-1}$ kanamicina; $\mathrm{pH}$ 6.9-7.6; osm 298-310). A continuación, se evaluaron los parámetros seminales utilizando técnicas estándar de laboratorio (Martín Rillo et al., 1996). Solamente aquellos eyaculados con $\geq 200$ x 106 espz $\mathrm{mL}^{-1}$ y con una calidad espermática de $\geq$ $85 \%$ espermatozoides con morfología normal, $\geq 75 \%$ de mótiles $\mathrm{y} \geq 80 \%$ de viables fueron seleccionados para la criopreservación. Los eyaculados seleccionados fueron dispensados en tubos de $50 \mathrm{~mL}$ e introducidos en una nevera a $17{ }^{\circ} \mathrm{C}$. Una vez a ésta temperatura, los tubos fueron depositados en cajas de poliespan y transportados al Laboratorio de Andrología del Hospital Clínico Veterinario de la Universidad de Murcia. En el laboratorio, se contrastó de nuevo la calidad espermática y aquellos eyaculados que mantenían la calidad arriba mencionada fueron procesados para su criopreservación.

La congelación se realizó en pajuelas de $0.5 \mathrm{~mL}$ siguiendo el procedimiento originalmente descrito para pajuelas de $5 \mathrm{~mL}$ por Westendorf et al. (1975) y posteriormente adaptado para pajuelas de $0.5 \mathrm{~mL}$ por Thurston et al. (1999) y Carvajal et al. (2004). La fracción rica diluida $1: 1(\mathrm{v} / \mathrm{v})$ en BTS y conservada a $17{ }^{\circ} \mathrm{C}$ fue centrifugada a $2400 \mathrm{x}$ g durante $3 \mathrm{~min}$. Una vez eliminado el sobrenadante por aspiración, el sedimento espermático se diluyó con LEY $(80 \% \mathrm{v} / \mathrm{v}$, $310 \mathrm{mM} \beta$-lactosa, $20 \% \mathrm{v} / \mathrm{v}$ yema de huevo y $100 \mu \mathrm{g}$ $\mathrm{mL}^{-1}$ sulfato de kanamicina; $\mathrm{pH} 6.2 ; 330 \pm 5 \mathrm{mOsmol}$ $\mathrm{kg}^{-1}$ ) hasta una concentración de $1.5 \times 10^{9}$ espz $\mathrm{mL}^{-1}$. A continuación, se procedió a un enfriamiento lento y progresivo de los espermatozoides diluidos hasta una temperatura de $5^{\circ} \mathrm{C}$ mediante su deposición en una vitrina térmica durante $2 \mathrm{~h}$. Una vez a $5{ }^{\circ} \mathrm{C}$, los espermatozoides se re-diluyeron LEYGO (89.5\% LEY, $9 \%$ glicerol y 1.5\% Equex STM v/v; pH 6.2 y $1145 \pm$ $17 \mathrm{mOsmol} \mathrm{kg}^{-1}$ ) hasta una concentración espermática final de $1 \times 10^{9}$ espz $\mathrm{mL}^{-1}$. Inmediatamente después, se procedió al envasado y sellado mecánico en pajuelas de $0.5 \mathrm{~mL}$. Posteriormente las pajuelas fueron congeladas en un biocongelador programable, para luego ser inmersas en nitrógeno líquido $\left(\mathrm{LN}_{2}\right)$ y almacenadas en tanques, donde se conservaron hasta el momento de la descongelación.

Dos pajuelas de cada uno de los eyaculados de verraco fueron descongeladas a $\approx 1200$ ó $\approx 1800{ }^{\circ} \mathrm{C}$ $\min ^{-1}$. El contenido de cada una de las dos pajuelas para cada velocidad de descongelación fue fraccionado en dos mitades. Tras la correspondiente dilución en BTS, fueron conservadas durante $360 \mathrm{~min}$, una mitad a temperatura ambiente de laboratorio $\left(\approx 21-23^{\circ} \mathrm{C}\right)$ y la otra incubada a $39^{\circ} \mathrm{C}$ y $5 \%$ de $\mathrm{CO}_{2}$. A los $0,60,120,240$ y 360 min post-descongelación, se prepararon alícuotas ( $\approx 6 \times 10^{6}$ células) y se determinó la producción de ROS, motilidad y viabilidad.

\section{Motilidad y calidad espermática}

Las muestras espermáticas descongeladas fueron diluidas gradualmente en BTS, hasta una concentración de $30 \times 10^{6}$ espz mL $\mathrm{mL}^{-1}$, para la evaluación de la motilidad mediante un sistema de análisis computarizado (CASA), siguiendo el procedimiento descrito por Cremades et al. (2005). Para cada evaluación, se colocaron $4 \mu \mathrm{L}$ de semen en una cámara Makler, previamente atemperada a $39^{\circ} \mathrm{C}$ y se analizaron 3 campos, evaluando un mínimo de 100 espz muestra ${ }^{-1}$. Los parámetros analizados fueron los siguientes: porcentaje total de espermatozoides mótiles (\%TSM) y porcentaje de espermatozoides con 
movimiento progresivo rápido $\left(\% \mathrm{RPS},>50 \mu \mathrm{m} \mathrm{s}^{-1}\right)$.

\section{Integridad de las membranas plasmática y acrosomal}

La integridad de las membranas plasmática y acrosomal fue valorada mediante una triple tinción fluorescente, basada en la descrita previamente para espermatozoides de vacuno por Nagy et al. (2003) y que contempla la utilización de una concentración final de 500 nM SYBR-14 [100 $\mu \mathrm{M}$ solución stock en dimetil sulfóxido (DMSO)], $75 \mu \mathrm{M}$ ioduro de propidio (IP; 1.5 $\mathrm{mM}$ en PBS) y $5 \mu \mathrm{g} \mathrm{mL} \mathrm{m}^{-1}$ de una solución de lecitina de Arachis hypogaea conjugada con ficoeritrina (PE-PNA; $1 \mathrm{mg} \mathrm{mL}^{-1}$ solución stock). Las muestras espermáticas congeladas-descongeladas fueron re-diluidas en BTS hasta $30 \times 10^{6}$ espz $\mathrm{mL}^{-1}$, entonces $100 \mu \mathrm{L}\left(\approx 3 \times 10^{6}\right.$ células) de dicha dilución, fueron incorporados a tubos que contenían $15 \mu \mathrm{L}$ de la mezcla de los tres fluorocromos ( $5 \mu \mathrm{L}$ de solución stock de cada uno) y se incubaron en una estufa a $37{ }^{\circ} \mathrm{C}$ por $10 \mathrm{~min}$. Posteriormente se añadieron $400 \mu \mathrm{L}$ de PBS y se procedió al análisis de las muestras en el citómetro de flujo, equipado con un láser de argón (488 nm, $20 \mathrm{~mW})$. Se adquirieron

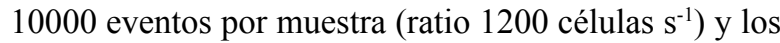
análisis fueron realizados con el software EXPO 2000. Los espermatozoides fueron clasificados en cuatro subpoblaciones diferentes: vivos con acrosoma íntegro (VAI), vivos con acrosoma dañado (VAD), muertos con acrosoma íntegro (MAI) y finalmente, muertos con acrosoma dañado (MAD). En los resultados se recogen los datos únicamente de la población VAI, al ser ésta la única fisiológicamente funcional.

\section{Determinación de la producción de ROS}

La producción de ROS en los espermatozoides vivos tras el proceso de congelación-descongelación fue determinada mediante la utilización combinada de los fluorocromos 2', 7'-diacetato de diclorodihidrofluoresceína, acetil ester (1 mM, CM$\mathrm{H}_{2}$ DCFDA) e ioduro de propidio (1.5 mM, IP), y cuantificada por citometría de flujo siguiendo una modificación del método descrito por Guthrie y Welch (2006). Cada muestra de espermatozoides congeladosdescongelados se sub-dividió en tres sub-muestras, las cuales fueron re-diluidas en BTS hasta una concentración de $\approx 6 \times 10^{6}$ células (dilución 1:5, v/v). A dos sub-muestras $(1000 \mu \mathrm{L})$, se le adicionaron $5 \mu \mathrm{l}$ de la solución de IP y $1 \mu \mathrm{L}$ de la solución de CM-H 2 DCFDA y se incubaron a $39^{\circ} \mathrm{C}$ con $5 \%$ de $\mathrm{CO}_{2}$ durante $30 \mathrm{~min}$. Así mismo, a una de estas dos sub-muestras se le adicionó, también previo a la incubación, $1 \mu \mathrm{L}$ de la solución de tert-butyl hidroperoxido (1 mM, TBHP) con el objetivo de inducir la generación de ROS. A la cantidad final de ROS producida en cada una de las dos sub-muestras se le restaron los niveles de ROS detectados en la tercera sub-muestra, a la cual solamente se le adicionaron $5 \mu \mathrm{L}$ de la solución de IP antes de la incubación (control). Los datos fueron analizados utilizando el software FCS Express, versión 3.0. La intensidad de fluorescencia de DCF (diclorofluoresceína) fue expresada como unidades de fluorescencia por millón de espermatozoides vivos (UF en $10^{12}$ espz). Adicionalmente, el porcentaje de células vivas (IP negativo) fue determinado.

\section{Análisis estadístico}

Para el análisis de los datos se utilizó el paquete estadístico SPSS versión 14.0. El procedimiento de descongelación y las condiciones de conservación de las muestras descongeladas sobre la calidad espermática y los niveles de ROS producidos en las muestras seminales congeladas-descongeladas, se evaluó mediante un análisis de varianza (ANOVA). Se utilizó un modelo mixto en el que el procedimiento de descongelación, la necesidad o no de incubar las muestras espermáticas, el tiempo de conservación de dichas muestras, el verraco y sus interacciones, fueron considerados como factores fijos. La pajuela de semen descongelada (dos por ensayo), considerada como replicado, fue el factor aleatorio. Cuando el ANOVA reveló efectos significativos, los valores fueron comparados usando la prueba de Bonferroni. La existencia o no de diferencias entre los porcentajes de espermatozoides viables (triple tinción) y vivos (ioduro de propidio negativo) se evaluó mediante una $t$ de Student. Las diferencias fueron consideradas estadísticamente significativas para $\mathrm{P}<0.05$. Los datos fueron expresados como media de mínimos cuadrados (LSM) \pm error estándar (SEM). El coeficiente de correlación de Spearman fue elegido para evaluar el grado de relación existente entre los niveles de ROS producidos y la calidad espermática.

\section{RESULTADOS Y DISCUSIÓN}

La motilidad (tanto el porcentaje de motiles totales como de rápidos progresivos) espermática fue diferente $(\mathrm{P}<0.01)$ entre las muestras no incubadas e incubadas, siendo dichos porcentajes siempre menores en las muestras incubadas (con valores medios de $44.73 \pm 0.91$ y $29.95 \pm 0.75$, respectivamente) que en las no incubadas $(51.53 \pm 0.85$ y $35.61 \pm 0.73)$. Sin embargo, no hubo diferencias en el porcentaje de espermatozoides viables $(58.78 \pm 0.99$ y $59.26 \pm 0.94$, para no incubadas e incubadas respectivamente). No se encontraron diferencias significativas $(\mathrm{P}>0.05)$ en la calidad espermática entre muestras descongeladas 
con ambas velocidades; esta circunstancia que difiere de los resultados de Roca et al. (2007) podría deberse a la buena calidad espermática observada a la descongelación en la mayor parte de los eyaculados utilizados, ya que estos autores contemplan cómo la velocidad no influye en aquellos eyaculados que muestran una buena calidad espermática a la descongelación, siendo su influencia muy significativa en aquellos en los que la calidad espermática a la descongelación es pobre.

Los porcentajes de espermatozoides vivos (no teñidos con ioduro de propidio) observados en las muestras espermáticas procesadas en los ensayos realizados para la determinación de ROS, fueron similares $(\mathrm{P}>0.05)$ al de viables en las muestras no incubadas y diferente $(\mathrm{P}<0.05)$ en las incubadas, donde el porcentaje de vivos fue siempre menor.

Los niveles de ROS (intensidad de fluorescencia DCF), tanto basales como inducidos fueron siempre significativamente $(\mathrm{P}<0.01)$ más elevados en las muestras incubadas. La velocidad de descongelación no tuvo influencia significativa $(\mathrm{P}>0.05)$ sobre la producción de ROS de las muestras espermáticas, independientemente de si fueron o no incubadas. Es difícil determinar la magnitud de dichos niveles; en primer lugar existen pocas experiencias con las que comparar estos resultados, y en segundo lugar, no están todavía establecidos umbrales de fluorescencia indicativos de funcionalidad espermática, con los que podamos asociar dichos resultados. Gadea et al. (2005) y Guthrie y Welch (2006) valoraron la producción espermática de ROS; sin embargo, los tiempos de incubación de los espermatozoides con los fluorocromos, el inductor utilizado, así como las unidades con que se expresaron los niveles de fluorescencia difieren entre ellos y, del protocolo utilizado en esta investigación. Sin embargo, los niveles de ROS apreciados en este trabajo son similares a los registrados por Hernández et al. (2007), quienes además mencionan que no difieren de los observados en las mismas muestras espermáticas, antes de someterlas al proceso de congelación-descongelación. Hecho este último, la ausencia de diferencias en la producción de ROS entre los espermatozoides vivos frescos o congeladosdescongelados, también constatado por Guthrie y Welch (2006). Lógicamente dicha circunstancia no es indicativa de que el proceso de criopreservación no induzca la producción de ROS, hecho ya demostrado con anterioridad en varias especies (Álvarez y Storey, 1992; Chantterjee y Gagnon, 2001), sino más bien es indicativa de que los espermatozoides que superan el proceso de criopreservación producen la misma cantidad de ROS que los frescos.

En las muestras no incubadas, es decir en aquellas que se conservaron a temperatura ambiente de laboratorio $\left(\approx 21-23{ }^{\circ} \mathrm{C}\right)$ durante $360 \mathrm{~min}$, no se registraron diferencias $(\mathrm{P}>0.05)$ en la producción de ROS a lo largo del tiempo, tanto en la producción basal como en la inducida (Figura 1), si bien a cada tiempo post-descongelación, la producción de ROS inducida fue siempre más elevada $(\mathrm{P}<0.01)$ que la basal. Se eligió conservarlas a temperatura ambiente porque es el procedimiento habitual utilizado con las dosis seminales, las cuales una vez descongeladas son conservadas a dicha temperatura hasta el momento de la inseminación. Esta circunstancia indica que las muestras espermáticas congeladasdescongeladas y mantenidas a temperatura ambiente no sufren estrés oxidativo, al menos durante las primeras seis horas. Por lo tanto, la pérdida progresiva de viabilidad en dichas muestras espermáticas aparentemente no está asociada a una mayor producción de ROS. Entre verracos, la producción de ROS varió significativamente $(\mathrm{P}<0.01)$, siendo dicha variación más relevante en los niveles inducidos (Figura 2).

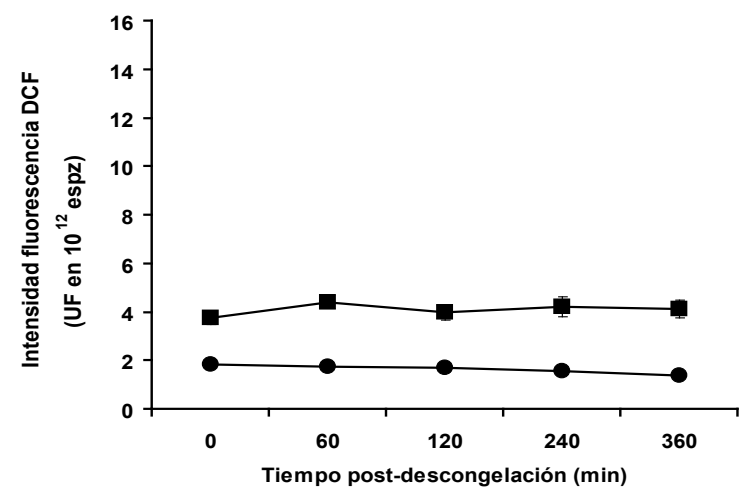

Figura 1. Efectos del tiempo post-descongelación sobre la intensidad de fluorescencia de DCF basal (•) e inducida (ø) en muestras espermáticas criopreservadas de verraco conservadas a temperatura ambiente de laboratorio $\left(\approx 21-23{ }^{\circ} \mathrm{C}\right)$ durante $360 \mathrm{~min}$

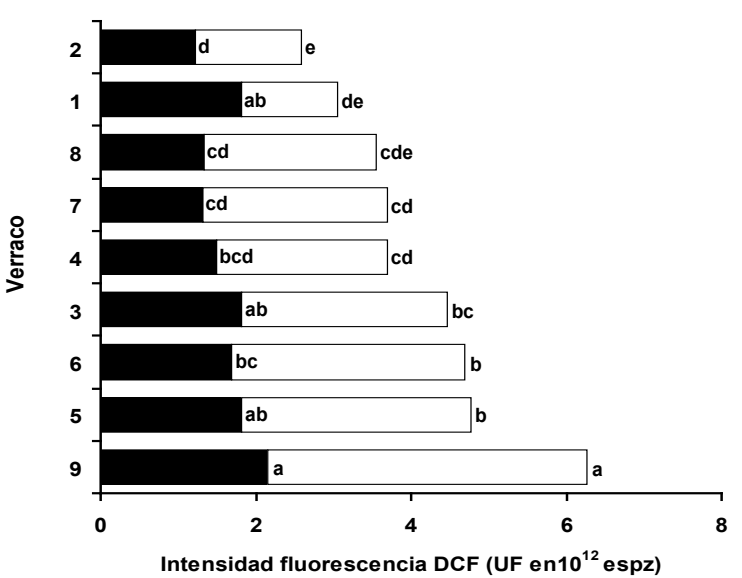

Figura 2. Diferencias en la intensidad de fluorescencia de DCF basal $(\square$, SEM $=0.14)$ e inducida $(\square+\square$, SEM $=0.35$ ) entre muestras espermáticas criopreservadas de porcino conservadas a temperatura ambiente de laboratorio $\left(\approx 21-23{ }^{\circ} \mathrm{C}\right)$ durante $360 \mathrm{~min}$. a-e indican diferencias significativas para $\mathbf{P}<0.05$ 
Respecto a las muestras espermáticas conservadas en incubación a $39{ }^{\circ} \mathrm{C}$ en presencia de un $5 \%$ de $\mathrm{CO}_{2}$, la producción de ROS, tanto basal como inducida, mostró una curva de producción ascendente $(\mathrm{P}<0.01)$ a lo largo de los $360 \mathrm{~min}$. Así, mientras que en los niveles basales (Figura 3a) el incremento fue significativo $(\mathrm{P}<0.01)$ a partir de los 120 min de incubación; en los niveles inducidos dicho incremento fue ya significativo $(\mathrm{P}<0.01)$ a partir de los 60 min (Figura 3b). Lo cual parece indicar que las muestras espermáticas congeladasdescongeladas en condiciones normales (a temperatura ambiente de laboratorio) no están sometidas a estrés oxidativo, pero son muy sensibles a cualquier agresión, en este caso la incubación.

a

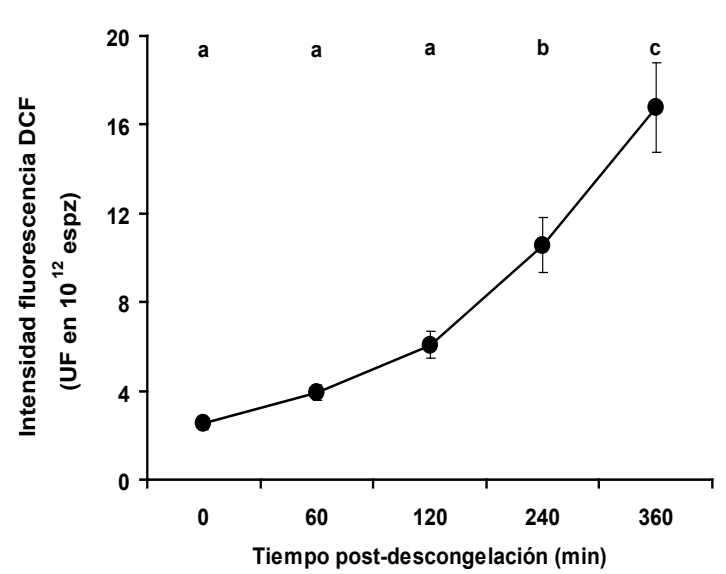

La producción de ROS, tanto la basal como la inducida, en las muestras espermáticas conservadas en incubación durante $360 \mathrm{~min}$, varió significativamente $(\mathrm{P}<0.01)$ entre verracos. El patrón de variación a lo largo del tiempo fue diferente entre la producción basal (Figura 4a) y la inducida (Figura 4b), siendo siempre mayor $(\mathrm{P}<0.01)$ en todos los verracos la inducida. Este hecho podría indicar diferencias entre eyaculados/ verracos en la posterior funcionalidad espermática. De confirmarse esta hipótesis, la medición de los niveles de ROS, en muestras espermáticas incubadas, podría predecir el potencial funcional de los espermatozoides congelados-descongelados de porcino. $\mathrm{b}$

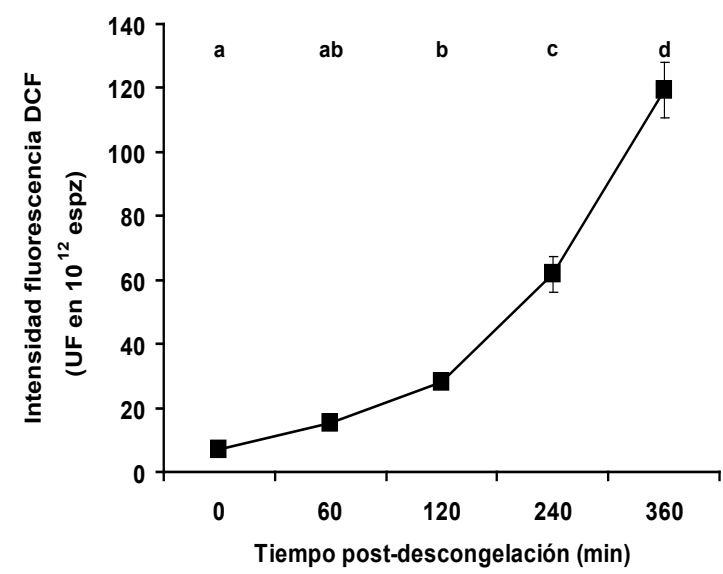

Figura 3. Efecto del tiempo post-descongelación sobre la intensidad de fluorescencia de DCF basal (a) e inducida (b) en muestras criopreservadas de porcino incubadas durante 360 min a $39{ }^{\circ} \mathrm{C}$ en presencia de un $5 \%$ de $\mathrm{CO}_{2}$
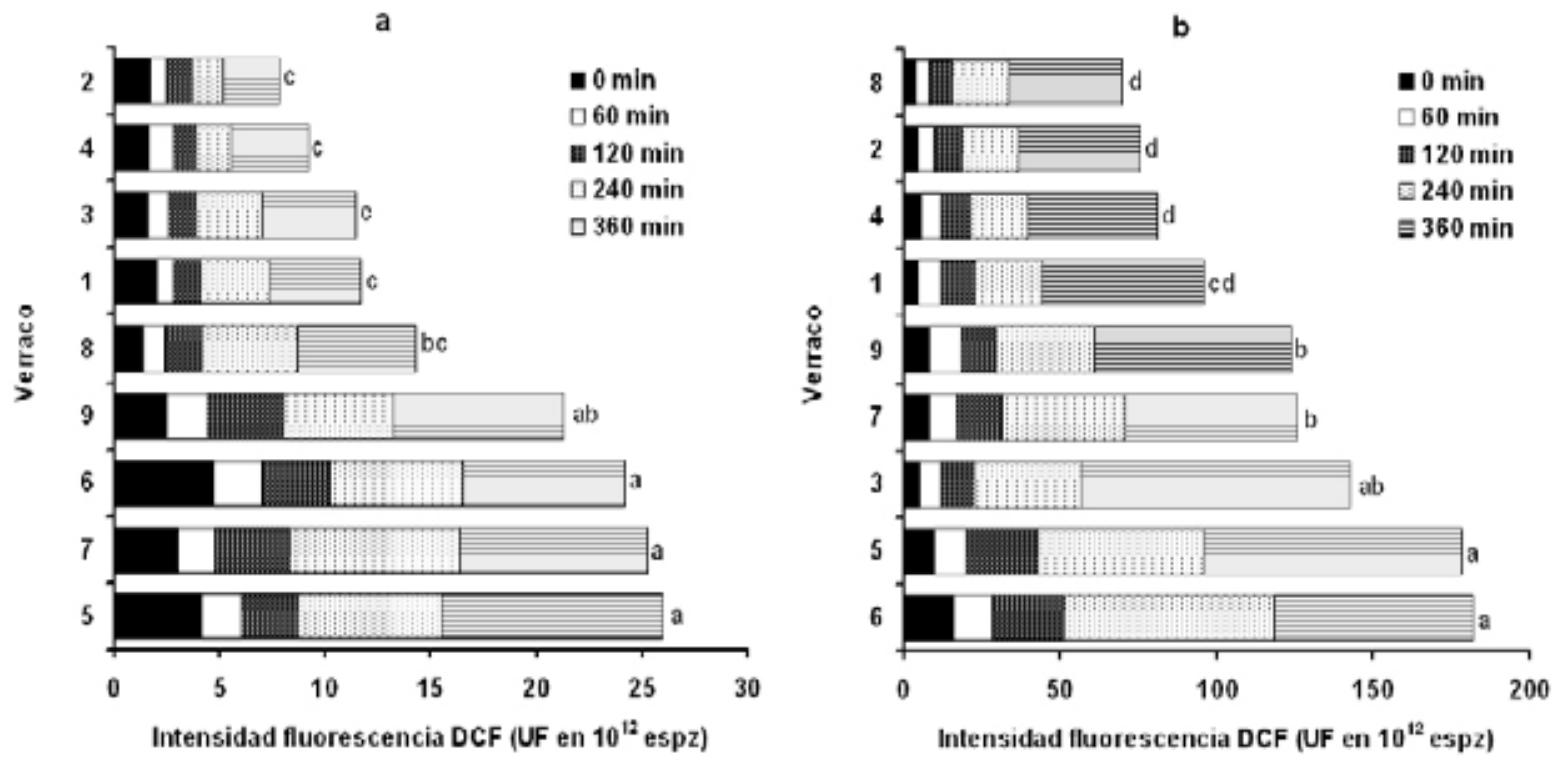

Figura 4. Diferencias en intensidad de fluorescencia de DCF basal (a, SEM = 1.36) e inducida $(b, S E M=4.32)$ en muestras espermáticas criopreservadas de porcino conservadas durante $360 \mathrm{~min}$ en incubación a $39^{\circ} \mathrm{C}$ en presencia de un $5 \%$ de $\mathrm{CO}_{2}$. a-d indican diferencia significativa para $\mathrm{P}<0.05$ 
La intensidad de fluorescencia de DCF basal e inducida, tanto en las muestras no incubadas como en las incubadas, observada en los espermatozoides vivos tras el proceso de criopreservación, estuvo significativamente correlacionada (Cuadro 1), con los porcentajes de espermatozoides mótiles totales, rápidos progresivos y viables observados a los $0,60,120,240$ y 360 min postdescongelación. Guthrie y Welch (2006) concluyeron en su trabajo que los niveles basales de ROS producidos por los espermatozoides viables a la descongelación, son muy bajos, razón por la cual consideran que dicha medición probablemente no pueda predecir la calidad o fertilidad de la muestra espermática.

Los resultados de este trabajo muestran la existencia de una significativa correlación negativa entre las unidades de fluorescencia de DCF y los parámetros de motilidad y viabilidad espermática de las muestras congeladas-descongeladas. Esta circunstancia confirma la relación directa existente entre estrés oxidativo y pérdida de calidad espermática. Además, demuestra que el test utilizado es adecuado para predecir calidad espermática. Es decir, ya inmediatamente después de la descongelación el test utilizado podría ayudar a predecir la pérdida funcional que experimentarán los espermatozoides congelados-descongelados. No obstante, antes de introducirla a la batería de pruebas de uso frecuente en andrología, deberíamos determinar rangos de intensidad de fluorescencia capaces de reflejar distintas situaciones de calidad espermática y para ello, todavía son necesarios más estudios.

Cuadro 1. Coeficientes de correlación de Rho de Spearman entre intensidad de fluorescencia DCF y parámetros de calidad espermática post-descongelación de muestras seminales de verraco conservadas durante 360 min a temperatura ambiente $(\approx 21-$ $23{ }^{\circ} \mathrm{C}$; no incubadas) o en incubación a $39^{\circ} \mathrm{C}$ y $5 \%$ de $\mathrm{CO}_{2}$ (incubadas)

\begin{tabular}{ccccc}
\hline \multirow{2}{*}{ Variable } & \multicolumn{3}{c}{ Intensidad fluorescencia DCF (UF/10 ${ }^{12}$ espz) } \\
\cline { 2 - 5 } & \multicolumn{2}{c}{ Muestras no incubadas } & \multicolumn{2}{c}{ Muestras incubadas } \\
\hline \multirow{2}{*}{ BSM (\%) } & $-33.8^{* *}$ & Inducida & Basal & Inducida \\
RPS (\%) & $-26.2 * *$ & $-48.2 * *$ & $-56.9 * *$ & $-53.8^{* *}$ \\
VAI (\%) & $-33.7 * *$ & $-50.7^{* * *}$ & $-58.6 * *$ & $-56.8 * *$ \\
\end{tabular}

TSM, espermatozoides mótiles totales; RPS, espermatozoides con movimiento progresivo rápido; VAI, espermatozoides vivos con acrosoma intacto. $* * \mathrm{P}<0.01$.

\section{CONCLUSIONES}

La velocidad de descongelación no tuvo influencia sobre la calidad espermática a la descongelación, ni sobre la producción de ROS.

La conservación de las dosis espermáticas congeladas-descongeladas en incubación a $39{ }^{\circ} \mathrm{C}$ y $5 \%$ de $\mathrm{CO}_{2}$, induce a la población de espermatozoides viables un incremento significativo de la producción de ROS, siendo además dicho incremento diferente entre eyaculados/verracos.

La producción de ROS por parte de los espermatozoides vivos a la descongelación, determinada mediante la técnica de fluorescencia y lectura por citometría $\mathrm{CM}-\mathrm{H}_{2}$ DCFDA estuvo significativamente correlacionada con los parámetros de calidad espermática; siendo dicha técnica de gran utilidad para evaluar la capacidad funcional de los espermatozoides congelados-descongelados, aunque se requieren más estudios para estandarizar la técnica y establecer umbrales de fluorescencia indicativos de pérdida de calidad espermática.

\section{LITERATURA CITADA}

Álvarez, J.G.; Storey, B.T. 1992. Evidence for increasing lipid peroxidative damage and loss of superoxide dismutase activity as a mode of sublethal cryodamage to human sperm during cryopreservation. J. Androl. 13:232-241.

Brouwers, J. F.; Silva, P. F. N.; Gadella, B. M. 2005. New assays for detection and localization of endogenous lipid peroxidation products in living boar sperm after BTS dilution or after freezethawing. Theriogenology 63:458-469.

Carvajal, G.; Cuello, C.; Ruiz, M.; Vázquez, J. M.; Martínez, E. A.; Roca, J. 2004. Effect of centrifugation before freezing on boar sperm cryosurvival. J. Androl. 25:389 -396.

Chatterjee, S.; Gagnon, C. 2001. Production of reactive oxygen species by spermatozoa undergoing cooling, freezing and thawing. Mol. Reprod. Dev. 59:451-458.

Cremades, T.; Roca, J.; Rodríguez-Martínez, H.; Abaigar, T.; Vázquez, J. M.; Martínez, E. A. 2005. Kinematic changes during the cryopreservation of boar spermatozoa. J. Androl. 5:610-618. 
De Lamirande, E.; Tasi, C.; Harakat, A.; Gagnon, C. 1998. Involvement of reactive oxygen species in human sperm acrosome reaction induced by A23187, Iysophosphatidylcholine, and biological fluid ultrafiltrates. J. Androl. 19:585-594.

Eriksson, B. M.; Rodríguez-Martínez, H. 2000. Effect of freezing and thawing rates on the post-thaw viability of boar spermatozoa frozen in FlatPacks and Maxi-satrws. Anim. Reprod. Sci. 63:205220.

Gadea, J.; Gumbao, D.; Matás, C.; Romar R. 2005. Supplementation of the thawing media with reduced glutathione improves function and the in vitro fertilizing ability of boar spermatozoa after cryopreservation. J. Androl. 26:749-756.

Guthrie, H. D.; Welch, G. R. 2006. Determination on intracellular reactive oxygen species and high mitochondrial membrane potential in Percolltreated viable boar sperm using fluorescenceactivated flow cytometry. J. Anim. Sci. 84:2089 -2100 .

Hernández, M.; Vázquez, J. M.; Martínez, E. A.; Roca, J. 2007. Oxidative stress during the cryopreservation of boar spermatozoa. Reprod. Fert. Dev. (En prensa).

Martin Rillo, S.; Martínez, E.; García Artiga; C., De Alba, C. 1996. Boar semen evaluation in practice. Reprod. Domest. Anim. 31:519- 526.

Nagy, S.; Cansen, J.; Topper, E. K.; Gadella, B. M. 2003. A triple-stain cytometric method to assess plasma and acrosome membrane integrity of cryopreserved bovine sperm immediately after thawing in presence of egg-yolk particles. Biol. Reprod. 68:1828 -1835.

O’ Flaherty, C.; de Lamirande, E. ; Gagnon, C. 2006. Positive role of reactive oxygen species in mammalian sperm capacitation: Triggering and modulation of phosphorylation events. Free Radical Biology \& Medicine 41:528- 540.

Roca, J.; Gil, M.; Hernández, M.; Parrilla, I.; Vázquez, J. M.; Martínez, E. A. 2004. Survival and fertility of boar spermatozoa after freeze-thawing in extender supplemented with butylated hydroxytoluene. J. Androl. 25:397-405.

Roca, J.; Rodríguez, M. J.; Gil, M. A.; Carvajal, G.; García, E. M.; Cuello, C.; Vázquez, J. M.; Martínez, E. A. 2005. Survival and in vitro fertility of boar spermatozoa frozen in the presence of superoxide dismutase and/or catalase. J. Androl. 26:15-24.

Roca, J.; Hernández, M.; Cremades, T.; Vázquez, J. M.; Martínez, E. A. 2007. Improvement of boar sperm cryosurvival by the optimization of cryopreservation conditions. Reprod. Fert. Dev. (En prensa).
Saleh, R. A.; Agarwal, A. 2002. Oxidative stress and male infertility: From research bench to clinical practice. J. Androl. 23:737 -752.

Thurston, L. M.; Watson, P. F.; Holt, W. V. 1999. Sources of variation in boar spermatozoa fertility following cryopreservation. Cryobiology 39:355.

Westendorf, P.; Richter, L.; Treu, H. 1975. Zur Tiefgefrierung von Ebersperma. Labor - und Besamungsergebnisse mit dem Hülsenberger Pailletten - verfahren. Dtsch. Tierärztl. Wschr. 82:261-267. 